\title{
Cost-effectiveness analysis of fesoterodine flexible dose in newly diagnosed patients with overactive bladder in routine clinical practice in Spain
}

This article was published in the following Dove Press journal:

ClinicoEconomics and Outcomes Research

26 September 2016

Number of times this article has been viewed

\author{
Carmen Peral' \\ Francisco \\ Sánchez-Ballester ${ }^{2}$ \\ José M García-Mediero ${ }^{3}$ \\ Jaime Ramos' \\ Javier Rejas' \\ 'Health Economics \& Outcomes \\ Research Department, Pfizer, \\ Alcobendas (Madrid), ${ }^{2}$ Department \\ of Urology, Hospital General \\ Universitario de Valencia, Valencia, \\ ${ }^{3}$ Department of Urology, Hospital \\ MD Anderson Cancer Center Madrid, \\ Madrid, Spain
}

Correspondence: Carmen Peral Health Economics \& Outcomes Department, Pfizer, Avenida de Europa, 20 B Parque Empresarial La Moraleja, 28108 Alcobendas (Madrid), Spain Email carmen.peral@pfizer.com
Objective: To carry out cost-effectiveness analysis from the Spanish National Health System perspective, of treating overactive bladder (OAB), in newly diagnosed patients with two flexible doses of fesoterodine in routine clinical practice.

Patients and methods: Economic evaluation of flexible-dose fesoterodine in newly diagnosed patients, including two treatment groups: standard escalating from 4 to $8 \mathrm{mg}$ or fast escalating to $8 \mathrm{mg}$. Costs were estimated from health care resources utilization related to $\mathrm{OAB}$, and were expressed in 2015 Euros. Quality-adjusted life-years (QALYs) were obtained from overactive bladder questionnaire-short form. Univariate and probabilistic sensitivity analyses were carried out. Results: Three hundred and ninety symptomatic OAB patients treated with fesoterodine and newly diagnosed (141 in fast escalating group and 249 in standard escalating) were analyzed. Adjusted health care total costs were not statistically different; difference $-€ 4$.1 (confidence interval: -153.3 ; 25.1) $P=0.842$. QALYs were higher in fast escalating to high dose vs standard escalating group, resulting in a cost of $-€ 16,020 / \mathrm{Q} A L Y$ gained for fast escalating vs standard escalating group.

Conclusion: When the cost-effectiveness threshold is set at a maximum value of $€ 30,000$ / QALY gained, fesoterodine fast escalating group was cost-effective vs standard escalating group $67.6 \%$ of the time. The treatment with fesoterodine, in female patients newly diagnosed, fast escalating to $8 \mathrm{mg}$ was a cost-effective option relative to escalating traditionally from 4 to $8 \mathrm{mg}$, in the management of OAB in routine clinical practice, from the Spanish National Health System perspective.

Keywords: antimuscarinic, fesoterodine, flexible dose, overactive bladder, cost-effectiveness

\section{Introduction}

Overactive bladder (OAB) is characterized by symptoms of urinary urgency with or without incontinence, often accompanied by daytime and nighttime frequency. ${ }^{1}$ It is caused by an overactive detrusor muscle, in many cases with no apparent cause, although a significant proportion of cases may be accompanied by a neurogenic dysfunction. ${ }^{1}$ The prevalence of $\mathrm{OAB}$ in the general adult population ranges from $14 \%$ to $16 \%,{ }^{2}$ usually associated with other health problems, such as sleep disorders, anxiety and/or depression, urinary tract and skin infections, etc, that not only lead to a considerable use of health care resources, but also affect the general well-being, activities of daily living, and health-related quality of life..$^{3-7}$

Antimuscarinics are the primary drugs used for the treatment of $\mathrm{OAB},{ }^{3}$ but response and tolerability vary among patients. Flexible doses have become increasingly important in society, especially among elderly patients and children. ${ }^{8}$ The use of flexible doses 
allows treatment to be better adapted to the patient's needs, by determining the most favorable balance for patients. ${ }^{8}$ Approximately $60 \%$ of patients with $\mathrm{OAB}$ choose to have the dose of their antimuscarinic increased, resulting in a favorable response in terms of disease management without increasing adverse effects. ${ }^{8}$ Flexible doses are defined as the capacity of a treatment to shift within a certain range, in which the drug is shown to be safe, while still exerting the desired therapeutic effect. ${ }^{9,10}$ Many conditions and needs of the patient may affect the treatment and benefit from the use of flexible doses, such as tolerability, safety, severity, and other clinical and demographic characteristics that the patients may present. The possibilities offered by the use of flexible doses directly affect how doctors and patients adjust treatment to maximize therapeutic response while controlling the occurrence of adverse effects. ${ }^{11}$

Fesoterodine is an antimuscarinic indicated for the symptomatic treatment of OAB and can be given in flexible doses. ${ }^{11-14}$ In a study based on the analysis of data from two flexible-dose clinical trials of fesoterodine, Cardozo et $\mathrm{al}^{15}$ observed that the highest dose of the drug was more effective in patients with more severe OAB symptoms, that is, those who had at least two episodes a day of urinary incontinence with urgency. However, dose escalation can lead to increased use of health care resources (medical visits, use of pads, or concomitant drugs) because of a delay in achieving greater effectiveness in symptom control. ${ }^{11}$ Therefore, in routine clinical practice, some clinicians prescribe high doses of fesoterodine, from the time of first treatment in newly diagnosed patients (<12 months). ${ }^{16}$

Given the limited health care resources of the National Health Service (NHS), economic evaluations of cost-effectiveness provide evidence for deciding on the most appropriate use of resources. To date, economic evaluations with antimuscarinic drugs have not addressed the cost-effectiveness of flexible doses, ${ }^{17-19}$ despite this being a routine practice in the treatment of these patients in real life. ${ }^{16}$ Therefore, the purpose of this study is to conduct a cost-effectiveness analysis (CEA) from the perspective of Spain's NHS. This analysis considers patients newly diagnosed ( $<12$ months of history) with symptomatic OAB, who are on treatment with flexible doses of fesoterodine, scaling from the traditional 4 to $8 \mathrm{mg}$, compared with fast escalation to $8 \mathrm{mg}$.

\section{Patients and methods Economic model}

To carry out this economic evaluation, a decision tree model was designed that reflects the titration or escalation of the fesoterodine dose from the start of the treatment (Figure 1). Each branch of the model represents a type of regimen followed by the clinician treating the OAB with fesoterodine, depending on the starting dose and the changes in symptoms and tolerability of the antimuscarinic. However, the economic analysis compares a starting regimen with a fast escalation to high dose versus a regimen with standard scaling both from low doses of fesoterodine $4 \mathrm{mg}$.

Following the product characteristics, the recommended starting dose of Fesoterodine is $4 \mathrm{mg}$ once daily. Based upon individual response and tolerability, the dose may be increased to $8 \mathrm{mg}$ once daily, with a maximum daily dose of $8 \mathrm{mg}$. The total treatment effect was between 2 and 8 weeks. Therefore, it is recommended by evaluating the efficacy in each individual patient after 8 weeks of treatment.

Taking this into account and based upon individual response, two groups were compared; the traditional escalating group and the fast escalation to $8 \mathrm{mg}$ group.

\section{Source data}

To populate the economic model, use of health care resources and effectiveness - expressed in terms of qualityadjusted life-years (QALYs) gained - were analyzed from an observational, cross-sectional/retrospective, multicenter study involving specialists in urology and gynecology from 88 private and public centers, representative of Spain as a whole according to geographical density. ${ }^{16}$ The sampling of centers was done randomly, without replacement based on the census available in urology and gynecology clinics, whereas the patients included were selected through a systematic sampling procedure from those who met the following screening criteria: patients of both sexes, aged $\geq 18$ years, diagnosed with OAB according to routine clinical practice, and who had started treatment with an antimuscarinic that might allow for dose titration (flexible doses; Figure 1). Patients undergoing any type of surgery on the lower urinary tract, who had given birth in the previous year, were unable to complete health questionnaires in Spanish, were excluded. All patients had to give their informed consent in writing. The study was approved by the ethics committee of the Hospital General Universitario de Valencia, and was conducted in compliance with the principles established in the Declaration of Helsinki for studies in humans.

All patients must have had two visits prior to the study visit, with information on the titration of the antimuscarinic drug with which they were being treated. The time between the study visit and the previous visits must have been at 


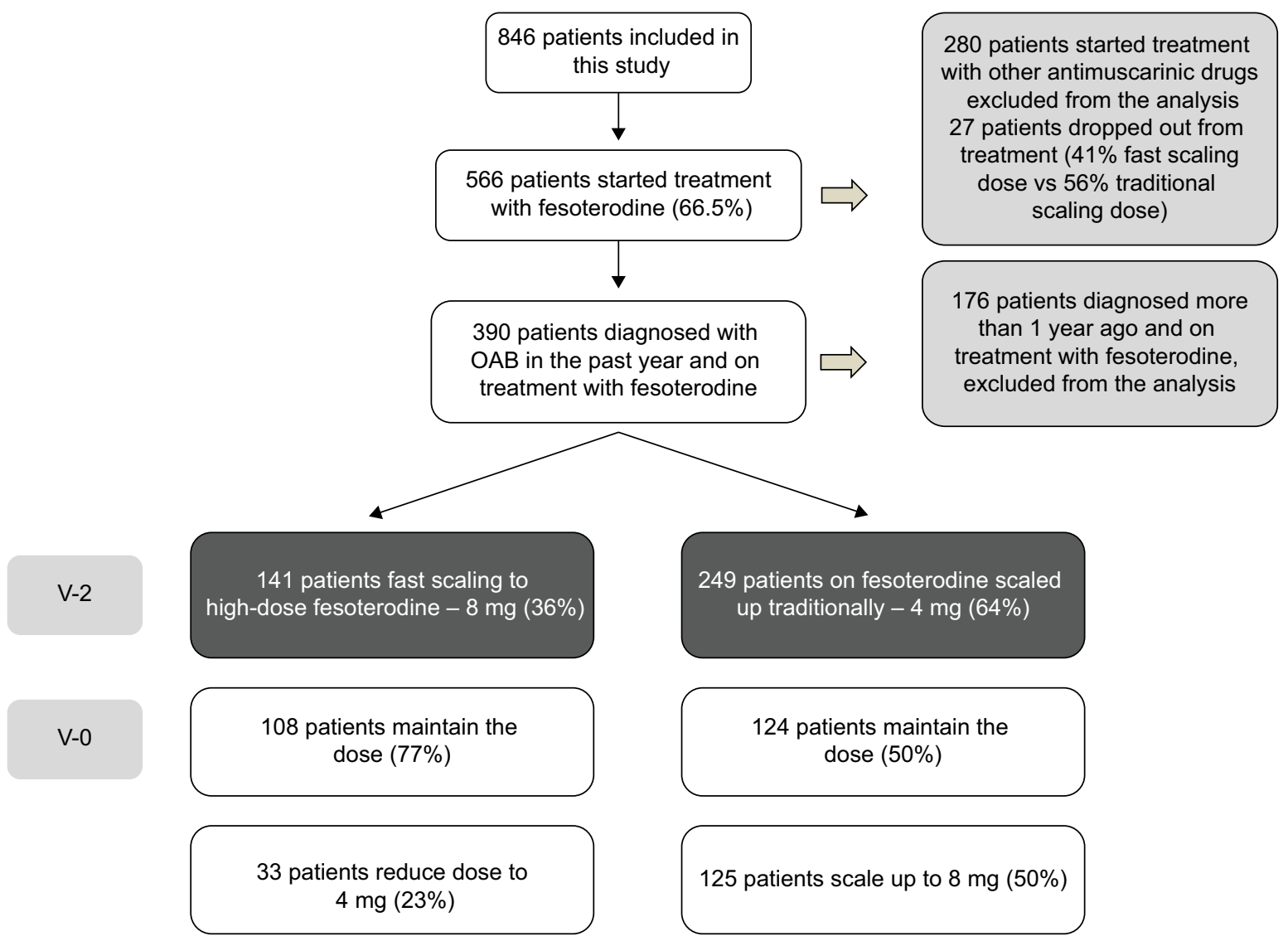

Figure I Flow chart showing the change of treatment during the study.

Notes: V-2: Baseline visit. V-0: Study visit. Prescribed regimens during the study are shown; from the baseline visit, showing the number of patients who entered the study with the inclusion criteria; and at the study visit, showing the flows of patients who maintained their original treatments, changed the dose, or changed treatment. Abbreviation: $O A B$, overactive bladder.

least 8 weeks. During the visit at which the treatment was started, the following were collected: demographic data, comorbidities, clinical history of the OAB, and treatment prescribed for the $\mathrm{OAB}$ and doses. In the first follow-up visit after the start of treatment, the following, if available, were collected: data on change of doses, reason for change (side effects, lack of clinical benefit, lack of treatment compliance or other), and who requested the change. During the study visit, the following, if available, were collected again: data on change of doses and/or treatment, reason for change and who requested it, and concomitant medication. During the study visit, the use of health care resources due to $\mathrm{OAB}$ from the start of treatment was evaluated. In addition to the dose and days of treatment with the antimuscarinic drug, information on the number of absorbents used daily, visits to primary care doctors and specialists, and visits to hospital outpatient clinics and emergency rooms were also collected.

In order to evaluate treatment adherence, during the study visit, patients were given the Spanish (Spain) version of the Morisky-Green Medication Adherence Scale. ${ }^{20}$
For this economic evaluation, patients with a recent diagnosis of OAB were selected; patients' OAB could not exceed 12 months of history and they had to be on treatment with a fast scaling to high-dose fesoterodine or have their doses scaled up in the standard way, so that dose flexibility could be analyzed. In addition, fesoterodine was chosen to be the single drug in order to avoid any confusion that might arise from including two drugs which, though similar, have different pharmacokinetic properties. Fesoterodine was chosen because its numerical representation was more in the study sample.

\section{Costs and use of resources}

The costs included in this study, from the perspective of the Spanish NHS, were related to the antimuscarinic drug based on dose and days of treatment, public selling price + VAT and after deducting $7.5 \%$ of the price according to the corresponding royal decree (8/2010), use of health care resources (visits to primary care doctors and to specialists, hospital outpatient visits and emergency room visits), and use of absorbents and concomitant medication for comorbidities directly associated with OAB (Table 1). The costs were expressed in 2015 Euros. $^{21,22}$ 
diseases, spinal stenosis, and spine surgery. In addition, a multiple linear regression analysis was carried out to observe the associated variables (adjusted for covariates).

A descriptive and univariate statistical analysis was performed with the mean and median values, the standard deviation and $95 \%$ confidence intervals in parametric variables and median and interquartile ranges in nonparametric variables, after verifying the normality of the distribution with the Kolmogorov-Smirnov test. In the bivariate analysis the following tests were used: analysis of variance, chi-squared, Pearson correlation coefficient, and paired sample $t$-test, according to the data distribution. The confidence interval of the mean differences was calculated by resampling (bootstrapping) with 1,000 iterations. SPSS for Windows, version 19 (IBM Corporation, Armonk, NY, USA), was used to establish the statistical significance for $P$-values at $<0.05$.

\section{Results}

A total of 390 patients with newly diagnosed OAB (141 in the fast scaling high-dose group and 249 in the traditional dose-scaling group), who received antimuscarinic treatment with fesoterodine, were drawn from the study to carry out this economic analysis. A significantly higher percentage of patients remained on the fast scaling high dose of $8 \mathrm{mg}$ throughout the study, compared with those who started with the dose of $4 \mathrm{mg}$ (traditional dose-scaling group) (chisquared $=25.7 ; P<0.001)$.
Table 2 shows the sociodemographic characteristics of the groups analyzed. The group that started treatment with fast scaling high doses not only had a higher proportion of females but also had fewer months of diagnosed OAB than the standard dose-scaling group (Table 2). Significant differences were observed in the mean duration of treatment with fesoterodine: 157.2 days (high-dose group) compared with 180.8 days (standard dose-scaling group); $P=0.005$. However, there were no significant differences in the level of adherence as assessed by the Morisky-Green Medication Adherence Scale: $58.2 \%$ vs $52.6 \% ; P=0.341$.

The difference in adjusted overall health care costs was not statistically significant between fesoterodine regimens (Table 3): difference of -€64.1 (confidence interval: -153.3 ; $25.1) ; P=0.842$. However, the disaggregated cost analysis showed statistically significant differences in accumulated cost for primary care visits ( $€ 53.4$ vs $€ 81.9 ; P=0.002$ ), cost for absorbents ( $€ 59.9 \mathrm{vs} € 100.0 ; P=0.014$ ) and concomitant medication ( $€ 70.1$ vs $€ 110.8 ; P=0.016$ ), which offset the significantly higher cost for antimuscarinic medication in the fast scaling high-dose fesoterodine group; $€ 419.2$ vs $€ 325.2 ; P<0.001$ (Table 3 ). These differences in cost factors were due to a different frequency in the use of health care resources between groups. Thus, a lower number of visits to primary care doctors $(1.1$ vs $1.7 ; P=0.05)$ or to the specialist ( 2.1 vs $2.4 ; P=0.030$ ) was observed, in favor of the fast scaling high-dose fesoterodine group compared with

Table 2 Sociodemographic characteristics of patients with both treatments included in the study

\begin{tabular}{|c|c|c|c|}
\hline Sociodemographic characteristics & $\begin{array}{l}\text { Fesoterodine: fast dose scaling to } 8 \mathrm{mg} \\
(\mathrm{n}=\mid \mathbf{4 1})\end{array}$ & $\begin{array}{l}\text { Fesoterodine: standard dose scaling } \\
(\mathrm{n}=\mathbf{2 4 9})\end{array}$ & *P-value \\
\hline Age, years & $61.9(12.9)[59.8 ; 64.1]$ & $61.1(11.5)[59.6 ; 62.5]$ & 0.520 \\
\hline Sex (\%), females & $87.9 \%$ & $67.5 \%$ & $<0.001$ \\
\hline BMI $\left(\mathrm{kg} / \mathrm{m}^{2}\right)$ & $26.0(5.6)[25.1 ; 27.0]$ & $26.3(3.6)[25.9 ; 26.8]$ & 0.606 \\
\hline History of $O A B$ & $5.6(2.4)[5.2 ; 6.0]$ & $6.1(2.2)[5.9 ; 6.4]$ & 0.029 \\
\hline Number of comorbidities & $2.7(2.8)[2.2 ; 3.2]$ & $2.5(2.2)[2.2 ; 2.8]$ & 0.468 \\
\hline Hypertension & $31.2 \%$ & $38.2 \%$ & 0.205 \\
\hline Common urinary tract infections & $34.8 \%$ & $30.5 \%$ & 0.455 \\
\hline Insomnia & $22.7 \%$ & $20.1 \%$ & 0.632 \\
\hline Depression & $19.1 \%$ & $16.5 \%$ & 0.595 \\
\hline Diabetes mellitus & $15.6 \%$ & $14.1 \%$ & 0.790 \\
\hline Obesity & $14.9 \%$ & $16.1 \%$ & 0.872 \\
\hline Rheumatic diseases & $11.3 \%$ & $12.4 \%$ & 0.873 \\
\hline Cardiovascular diseases & $10.6 \%$ & $4.4 \%$ & 0.031 \\
\hline Osteoarthritis & $8.5 \%$ & $10.0 \%$ & 0.752 \\
\hline Perineal surgery & $6.4 \%$ & $2.8 \%$ & 0.080 \\
\hline Stroke/TIA & $6.4 \%$ & $2.4 \%$ & 0.092 \\
\hline Angina & $5.0 \%$ & $0.4 \%$ & 0.007 \\
\hline Abdominal aorta & $3.5 \%$ & $0.8 \%$ & 0.050 \\
\hline Chronic pelvic pain & $2.1 \%$ & $3.2 \%$ & 0.761 \\
\hline Disc diseases, spinal stenosis, spine surgery & $0.7 \%$ & $4.4 \%$ & 0.042 \\
\hline
\end{tabular}

Note: $* P$-value between groups; values expressed as mean (SD) or as a \%. [Upper and lower range.]

Abbreviations: BMI, body mass index; OAB, overactive bladder; SD, standard deviation; TIA, transient ischemic attack. 
Table 3 Use of resources and costs (2015 Euros) by treatment group

\begin{tabular}{|c|c|c|c|c|}
\hline Use of resources & $\begin{array}{l}\text { Fesoterodine: baseline fast } \\
\text { dose scaling }(n=|4|)\end{array}$ & $\begin{array}{l}\text { Fesoterodine: standard } \\
\text { dose scaling }(n=249)\end{array}$ & Mean difference & $P$-value* \\
\hline \multicolumn{5}{|c|}{ Medical care (mean number of visits) } \\
\hline Primary care visits & I.I (0.8; I.4) & $1.7(1.4 ; 2.0)$ & & 0.005 \\
\hline Specialist outpatient visits & $2.1(1.8 ; 2.4)$ & $2.4(2.3 ; 2.6)$ & & 0.030 \\
\hline Emergency room visits & $0.0(-0.0 ; 0.1)$ & $0.2(0.1 ; 0.3)$ & & 0.083 \\
\hline Specialist hospital visits & $0.5(0.3 ; 0.8)$ & $0.7(0.5 ; 0.9)$ & & 0.193 \\
\hline$\%$ Patients using absorbents & 39.0 & 5.0 & & 0.299 \\
\hline$\%$ Concomitant medication used & 23.0 & 18.0 & & 0.332 \\
\hline \multicolumn{5}{|l|}{ Costs $€$ (mean cost per patient) } \\
\hline Total costs, $€$ & $840.7(770.9 ; 910.4)$ & 904.7 (853.1; 956.3) & $-64.1(-153.3 ; 25.1)$ & 0.842 \\
\hline Medical care, $€$ & $351.3(295.7 ; 406.9)$ & $468.7(427.5 ; 509.8)$ & $-117.3(-118.4 ;-46.2)$ & 0.001 \\
\hline Primary care visits & $53.4(39.1 ; 67.7)$ & $81.9(71.4 ; 92.5)$ & $-28.5(-45.3 ;-9.7)$ & 0.002 \\
\hline Specialist outpatient visits & $233.7(209.2 ; 258.1)$ & $275.6(257.5 ; 293.7)$ & $-41.9(-77.4 ;-8.2)$ & 0.009 \\
\hline Emergency room visits & $8.5(-13.3 ; 30.2)$ & $32.7(16.6 ; 48.9)$ & $-24.3(-52.1 ; 3.6)$ & 0.087 \\
\hline Specialist hospital visits & $55.8(31.8 ; 79.8)$ & $8.4(60.6 ; 96.2)$ & $-22.6(-53.3 ; 8.1)$ & 0.149 \\
\hline Absorbents funded, $€$ & $59.9(35.0 ; 84.8)$ & $100.0(81.6 ; 118.4)$ & $-40.1(-71.9 ;-8.2)$ & 0.014 \\
\hline Antimuscarinic drugs, $€$ & $419.2(407.3 ; 431.1)$ & $325.2(316.4 ; 334.0)$ & 94.0 (78.8; 109.2) & $<0.001$ \\
\hline Concomitant medication, $€ * *$ & $70.1(44.1 ; 96.0)$ & II $0.8(91.6 ; 130.0)$ & $-40.7(-72.9 ;-10.0)$ & 0.016 \\
\hline
\end{tabular}

Notes: *P-value between groups. **Drug treatment for comorbidities associated with OAB (depression, skin infections, urinary tract infections, insomnia, and others) (cost for drug only). Values and differences are adjusted for covariates: sex, history of OAB, total days of treatment, and the following comorbidities: perineal surgery, perineal aortic surgery, stroke, cardiovascular disease, angina, and disc diseases, spinal stenosis, and spine surgery. Data are presented as mean values ( $95 \%$ confidence interval) Abbreviation: $O A B$, overactive bladder.

Table 4 Base case scenario in the cost-effectiveness analysis of fesoterodine in flexible doses

\begin{tabular}{llll}
\hline & $\begin{array}{l}\text { Fesoterodine: } \\
\text { fast dose } \\
\text { scaling }\end{array}$ & $\begin{array}{l}\text { Fesoterodine: } \\
\text { standard dose } \\
\text { scaling }\end{array}$ & Difference \\
\hline QALYs & $0.013(0.010 ;$ & $0.009(0.006 ;$ & 0.004 \\
& $0.016)$ & $0.011)$ & \\
Total costs, $€$ & $840.7(770.9 ;$ & $904.7(853.1 ;$ & $-€ 64.08$ \\
& $910.4)$ & $956.3)$ & $-€ 16,020$ \\
$\begin{array}{l}\text { ICER for fast dose- } \\
\text { scaling fesoterodine }\end{array}$ & - & \\
vs standard dose \\
scaling
\end{tabular}

the dose-scaling group (Table 3). In the base case scenario, the QALYs gained were higher in the fast scaling high-dose group vs the dose-scaling group (0.013 vs 0.009$)$, although the differences were not statistically significant. The ICER per QALY gained in the fast scaling high-dose group versus dose-scaling group was negative $(-€ 16,020)$, as a result of the ratio of a negative difference in costs $(-€ 64)$ divided by a positive gain in QALYs in the fast scaling high-dose group (Table 4).

\section{Sensitivity analysis}

The univariate sensitivity analysis of extreme values, in which the model's parameters that were considered the most sensitive varied by $\pm 25 \%$, showed that the option of starting treatment with fast scaling high doses of fesoterodine for $\mathrm{OAB}$ was dominant for most of the modified parameters related to treatment costs (fewer costs and more health effects; see the tornado chart). This shows the potential savings for the Spanish NHS (Figure 2), as the threshold of the ability to pay $€ 30,000 /$ QALY gained was cost-effective in the other parameters where it was nondominant. Further, the subgroup sensitivity analysis confirmed the robustness of the base case in most subgroups analyzed, showing a dominant or cost-effective ICER (with the threshold of $€ 30,000$ per QALY gained) in the fast escalating high-dose group versus the dose-scaling group, except in the subgroups of males with $\mathrm{OAB}$ and in patients with $\mathrm{OAB}$ with $>12$ months of history (Table 5).

The PSA with 5,000 simulations showed that, in 5.5\% of the iterations, the ICER of the fast escalating high-dose group was in the upper right quadrant of the cost-effectiveness graph (Figure 3A), indicating greater effectiveness, albeit with a higher cost; whereas for $4.0 \%$ of the time, the fast scaling high-dose group was less effective and with higher costs than the dose-scaling group (dominated option). Overall, $47.2 \%$ in the fast scaling high-dose group was dominant (more effective with lower costs) and for $43.4 \%$ of the time, it was less effective but with lower costs. The PSA showed that when the cost-effectiveness threshold was set at a maximum of $€ 30,000$ per QALY gained, the fast scaling high-dose group proved to be cost-effective vs the dose-scaling group in $67.6 \%$ of simulations performed with the ICER (Figure 3B). 


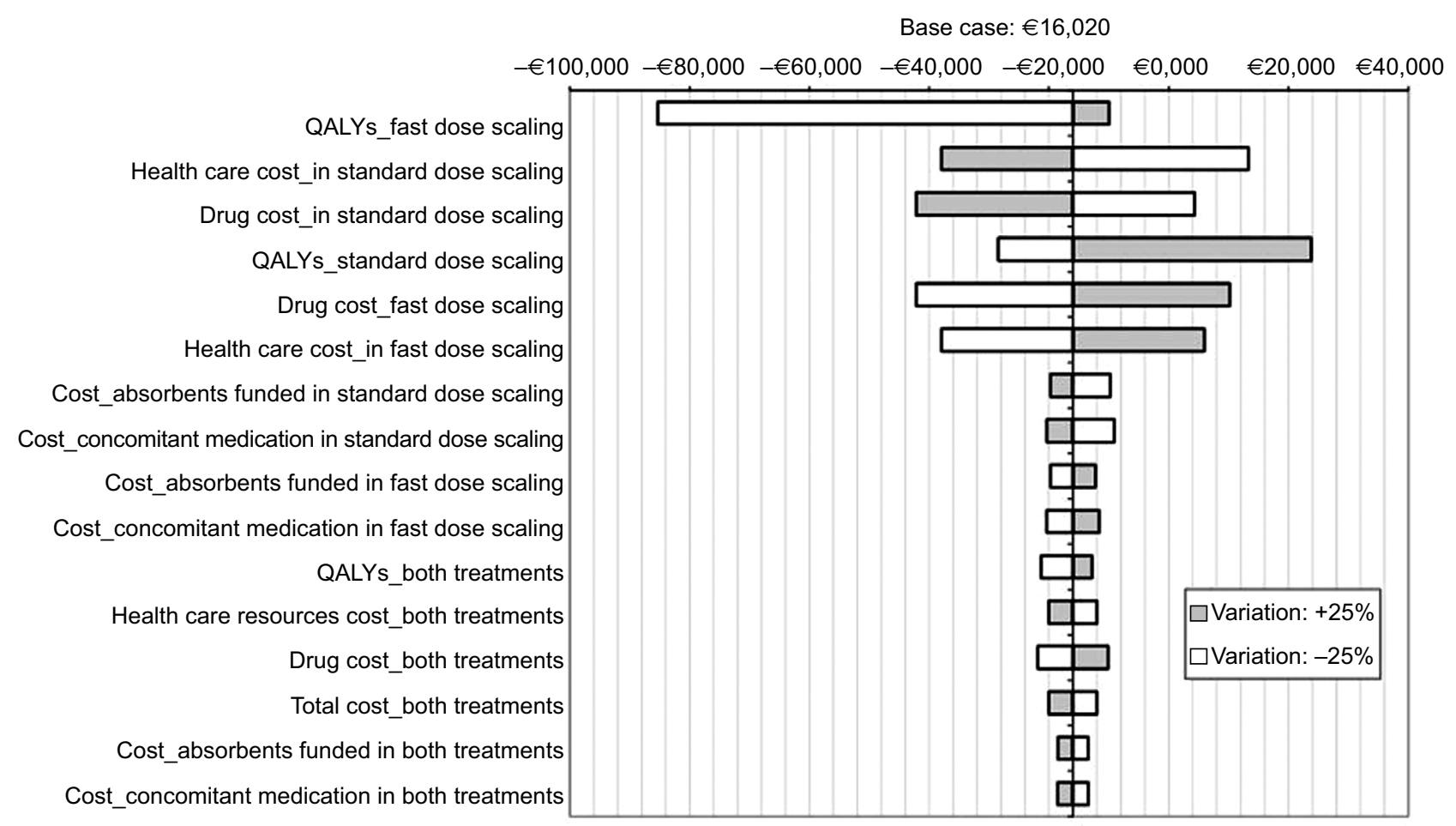

Figure 2 Univariate sensitivity analysis: tornado chart.

Note: Each variable is changed independently, by $\pm 25 \%$.

Abbreviation: QALYs, quality-adjusted life-years

Table 5 Sensitivity analysis in subgroups

\begin{tabular}{|c|c|c|c|c|}
\hline & Difference in QALYs & Difference in total costs & ICER & Change from base case \\
\hline Base case & 0.004 & $-€ 64.08$ & $-€ \mid 6,020$ & - \\
\hline Females & 0.005 & $-€ 93.49$ & $-€ \mid 8,697$ & $-17 \%$ \\
\hline Males & -0.001 & $€ 72.26$ & $-€ 72,263$ & Dominated \\
\hline Patients $<65$ years & 0.006 & $-€ 35.68$ & $-€ 5,946$ & $63 \%$ \\
\hline Patients $\geq 65$ years & 0.001 & $€|5.0|$ & $€ 15,010$ & $194 \%$ \\
\hline Vulnerable patients $>75$ years & 0.004 & $-€|| 8.5 \mid$ & $-€ 29,629$ & $-85 \%$ \\
\hline No comorbidity associated with $O A B$ & 0.002 & $-€ 36.48$ & $-€ \mid 8,239$ & $-14 \%$ \\
\hline $\begin{array}{l}\text { Patients with I+ comorbidity associated } \\
\text { with } O A B\end{array}$ & 0.002 & $€ 9.98$ & $€ 4,989$ & $131 \%$ \\
\hline Patients with no urine leakage & 0.003 & $€ 53.72$ & $€ 17,908$ & $212 \%$ \\
\hline Patients with urine leakage & 0.002 & $-€ 212.95$ & $-€ 106,474$ & $-565 \%$ \\
\hline Patients $>$ I year of history of $O A B$ & -0.004 & $€ I I I .67$ & $-€ 27,917$ & Dominated \\
\hline
\end{tabular}

Note: The differences in QALYs and costs represent the differences observed between fast dose-scaling fesoterodine vs standard dose scaling.

Abbreviations: ICER, incremental cost-effectiveness ratio; OAB, overactive bladder; QALYs, quality-adjusted life-years.

\section{Discussion}

This study comprised an economic evaluation of the use of an antimuscarinic drug (fesoterodine), given in flexible doses, in patients newly diagnosed with $\mathrm{OAB}$, in daily clinical practice in Spain, using flexible doses to prescribe two different dosages. In this way, its relative efficiency was estimated in routine clinical practice conditions. Numerous clinical studies have shown the effectiveness of using flexible doses of antimuscarinic drugs to treat symptomatic OAB. ${ }^{8-12,14,15}$ Data from observational studies, such as the study presented here, ${ }^{16}$ which give a more realistic view of daily practice, may also help to develop better therapeutic strategies, which complement those obtained in traditional clinical trials, and therefore it is also interesting to estimate effectiveness of drug use in these conditions. ${ }^{29}$

In different economic evaluations with fesoterodine published in Spain, where a CEA has been performed, the superiority of fesoterodine has been shown, compared with other drugs for the symptomatic treatment of OAB. ${ }^{17-19}$ These economic evaluations have shown that, compared 
A Incremental cost-effectivness of fesoterodine: maintained vs dose-scaling

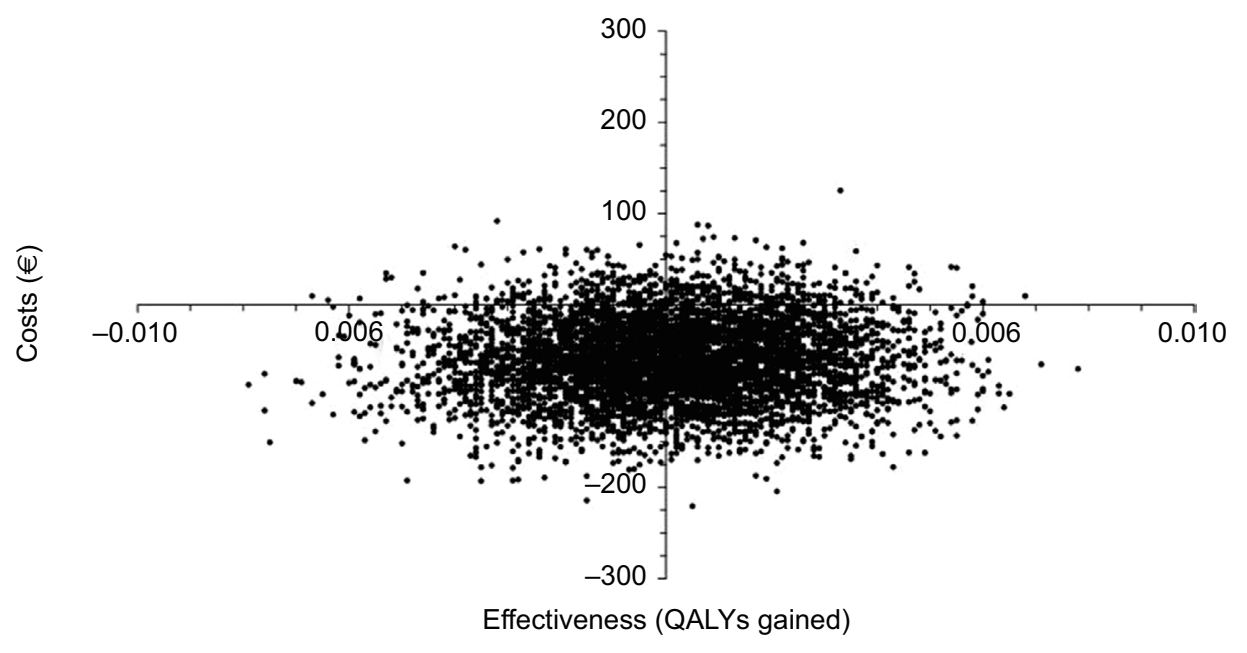

B

Acceptability curve

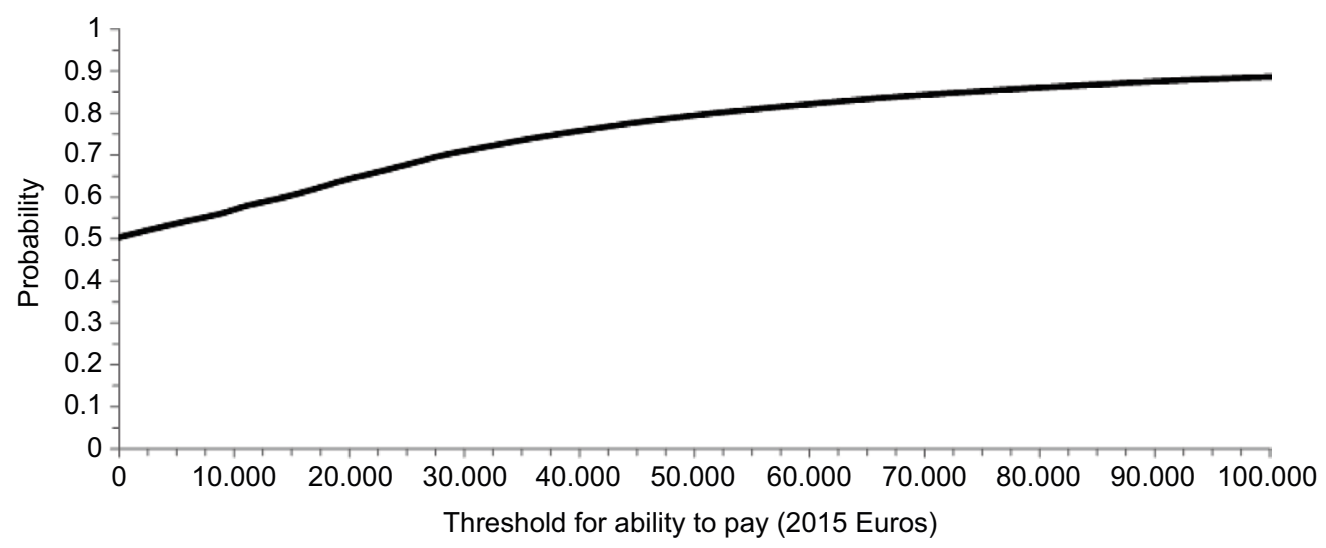

Figure 3 (A) Incremental cost-effectiveness graph and (B) acceptability curve.

Note: The acceptability curve shows the probability of fast-scaling fesoterodine being cost-effective vs standard dose scaling.

Abbreviation: QALYs: quality-adjusted life-years.

with solifenacin, tolterodine or mirabegron, fesoterodine has an ICER under the cost-effectiveness threshold normally accepted in Spain for inclusion in the pharmaceutical services of NHS. ${ }^{25}$ The economic superiority of fesoterodine compared with other antimuscarinic drugs available in our health care setting has also been shown in conditions of routine or real-life practice, indicating that fesoterodine can lead to health care savings in the treatment of OAB, which is NHS-funded, and offsetting its higher pharmacological cost with less use of health care resources, such as medical visits, absorbents, or concomitant medication related to OAB (antidepressants, anxiolytics, etc), in patients of any age and in vulnerable subjects. ${ }^{30-32}$ However, none of the above economic evaluations has addressed the cost-effectiveness of fesoterodine in flexible doses, which allows for two different dosages: a rapid scaling to high doses or the standard scaling according with the recommendation in the fesoterodine sum- mary of product characteristics. In our study, when flexible doses of fesoterodine were used in newly diagnosed patients, fast scaling to high doses proved to be a cost-effective treatment option in most of the situations analyzed according to the current recommendations in our health care setting. ${ }^{25,33}$

This economic evaluation has confirmed the findings of other economic evaluations with fesoterodine, which show that its biggest pharmacological cost (in this case due to the use of fast scaling to high doses versus conventional titration) comes with savings in other components of NHS-funded health care costs, namely, cost for absorbents, concomitant medication related to $\mathrm{OAB}$, and health care costs for medical visits to primary care and to specialists, which fully offset additional pharmacological costs. These results have been able to be replicated in various alternative scenarios and subgroups of patients, which fully justify this economic evaluation, although it may be considered unusual to compare 
two doses of the same drug, because it is rare to find similar economic evaluations in the scientific literature. ${ }^{34}$ One of the most sensitive factors in this economic evaluation was time since diagnosis of OAB. Thus, the results show that high doses of fesoterodine turn out to be cost-effective when the diagnosis of $\mathrm{OAB}$ is recent, that is, $<1$ year. But they are not cost-effective when patients have had OAB for $>12$ months, from the current perspective in Spain for the ability to pay per QALY gained, according to current recommendations. ${ }^{25,33}$ This suggests that clinicians should consider escalating fast to high doses of fesoterodine only if patients have had OAB for $<12$ months, because only in these circumstances is the greater pharmaceutical cost offset by savings in other components of health care costs, while there are more QALYs gained.

The findings of this economic evaluation could help health authorities and decision makers in health care in the process of making decisions that entail improvements in daily clinical practice (real world), although this study is not without its limitations. First, due to the study design, no data are available on the severity of the OAB at the start of treatment or on dose escalation, because doing this evaluation required bladder diaries that the patients had to complete over several days, tasks that are often used in clinical trials but not in routine practice. This has prevented us from knowing whether the groups were completely homogeneous at the start of treatment with fesoterodine. However, the advantage of pragmatic studies such as this one, which represent routine or real-life medical practice, may lie in their utility in health care decision making. Another possible limitation revolves around the costs used, since in this study no information on hospitalizations, cost per protocol (cost of side effects or switching), or additional testing (urodynamics, cultures, etc) was collected. Still, it should be noted that these patients usually do not require hospitalization, and this cost component might not be expected to change the results of the economic study. Further, the impact of possible fractures produced, particularly in vulnerable patients, on the use of health care resources, was not collected. However, this might not be a significant problem from an economic point of view, as has been observed in other economic evaluations carried out in our health care setting with antimuscarinic drugs. ${ }^{17-19}$ Finally, this evaluation was not performed from the society's perspective, because this study did not take into account variables such as payment for absorbents by the patient, travel costs, losses in productivity, or their impact on indirect costs.

With increasing pressure on payers and prescribers to make economic decisions regarding patients, data on cost-effectiveness should be taken into account more often in decision making. This is the first study to carry out an analysis of fesoterodine with different treatment regimens and show that treatment with fesoterodine scaling fast to high doses involves savings and more clinical benefits (in terms of QALYs gained) versus the standard titration of this drug.

\section{Conclusion}

According to the results from this study, treatment with fesoterodine fast scaling to $8 \mathrm{mg}$ may be considered a costeffective alternative for the Spanish NHS, compared with the traditional titration of this drug, from 4 to $8 \mathrm{mg}$, in the treatment of $\mathrm{OAB}$ in females who have had $\mathrm{OAB}$ for $<12$ months, in routine clinical practice.

\section{Author contributions}

FS-B and JMG-M contributed to the study conceptualization and design. CP, JR, and JR contributed to study conceptualization, methodology plan, and performed the analysis. All authors listed made substantial contributions to the study in conceptualization and/or study design, analysis and/or data interpretation, and manuscript preparation and/or review. All authors read, edited, and approved the final manuscript.

\section{Disclosure}

Carmen Peral and Javier Rejas are employees of Pfizer. Jaime Ramos is a former employee of Pfizer. The other authors report no conflicts of interest in this work.

\section{References}

1. Haylen BT, de Ridder D, Freeman RM, et al; International Urogynecological Association; International Continence Society. An International Urogynecological Association (IUGA)/International Continence Society (ICS) joint report on the terminology for female pelvic for dysfunction. Neurol Urodyn. 2010;29(1):4-20.

2. Irwin DE, Milsom I, Hunskaar S, et al. Population-based survey of urinary incontinence, overactive bladder, and other lower urinary tract symptoms in five countries: results of the EPIC study. Eur Urol. 2006;50(6): $1306-1314$.

3. Ouslander JG. Management of overactive bladder. N Engl J Med. 2004; 350(8):786-799.

4. Stewart WF, Van Rooyen JB, Cundiff GW, et al. Prevalence and burden of overactive bladder in the United States. World J Urol. 2003;20(6): 327-336.

5. Coyne KS, Zhou Z, Bhattacharyya SK, Thompson CL, Dhawan R, Versi E. The prevalence of nocturia and its effect on health-related quality of life and sleep in a community sample in the USA. BJU Int. 2003;92(9): 948-954.

6. Coyne KS, Payne C, Bhattacharyya SK, Revicki DA, Thompson C, Corey $\mathrm{R}$, Hunt $\mathrm{TL}$. The impact of urinary urgency and frequency on health-related quality of life in overactive bladder: results from a national community survey. Value Health. 2004;7(4):455-463.

7. Irwin DE, Milsom I, Koop Z, Abrams P, Cardozo L. Impact of overactive bladder symptoms on employment, social interactions and emotional well-being in six European countries. BJU Int. 2006;97(1):96-100.

8. Van Kerrebroeck PE, Heesakkers J, Berriman S, Padmanabhan Aiyer L, Carlsson M, Guan Z. Long-term safety, tolerability and efficacy of fesoterodine treatment in subjects with overactive bladder symptoms. Int J Clin Pract. 2010;64(5):584-593. 
9. Chapple CR, Rosenberg MT, Brenes FJ. Listening to the patient: a flexible approach to the use of antimuscarinic agents in overactive bladder syndrome. BJU Int. 2009;104(7):960-967.

10. Staskin D, Khullar V, Michel MC, Morrow JD, Sun F, Guan Z, Dmochowski R. Effects of voluntary dose escalation in a placebo-controlled, flexible-dose trial of fesoterodine in subjects with overactive bladder. Neurourol Urodyn. 2011;30(8):1480-1485.

11. Cardozo L, Hall T, Ryan J, Ebel Bitoun C, Kausar I, Darekar A, Wagg A. Safety and efficacy of flexible-dose fesoterodine in British subjects with overactive bladder: insights into factors associated with dose escalation. Int Urogynecol J. 2012;23(11):1581-1590.

12. Dmochowski RR, Peters KM, Morrow JD, et al. Randomized, doubleblind, placebo-controlled trial of flexible-dose fesoterodine in subjects with overactive bladder. Urology. 2010;75(1):62-68.

13. Fesoterodine: summary of product characteristics. Available from: http:// www.ema.europa.eu/docs/en_GB/document_library/EPAR__Product_ Information/human/000723/WC500040178.pdf

14. Wyndaele JJ, Schneider T, MacDiarmid S, Scholfield D, Arumi D. Flexible dosing with fesoterodine 4 and $8 \mathrm{mg}$ : a systematic review of data from clinical trials. Int J Clin Pract. 2014;68(7):830-840.

15. Cardozo L, Khullar V, Wang JT, Guan Z, Sand PK. Fesoterodine in patients with overactive bladder syndrome: can the severity of baseline urgency urinary incontinence predict dosing requirement? BJU Int. 2010;106(6):816-821.

16. Garcia-Mediero JM, Sánchez-Ballester F, Arumi D, Lizarraga I. Identificando perfiles de pacientes en el tratamiento de la vejiga hiperactiva. Estudio transversal, retrospectivo y multicéntrico. LXXX Congreso Nacional de Urología. 2015; Abstract C-83.

17. Angulo JC, Valpas A, Rejas J, Linden K, Kvasz M, Snedecor SJ. Cost effectiveness of fesoterodine and tolterodine for the treatment of overactive bladder with urge urinary incontinence in Spain and Finland. Clin Drug Invest. 2014;34(5):297-307.

18. Arlandis-Guzman S, Errando-Smet C, Trocio J, Arumi D, Rejas J. Costeffectiveness analysis of antimuscarinics in the treatment of patients with overactive bladder in Spain: a decision-tree model. BMC Urol. 2011;11:9.

19. Angulo JC, Sánchez-Ballester F, Peral C, et al. Cost effectiveness analysis of fesoterodine compared to mirabegron in first-line therapy setting for overactive bladder with urge urinary incontinence, from the Spanish National Health System perspective. Actas Urol Esp. Epub 2016 Mar 14.

20. Morisky DE, Green LW, Levine DM. Concurrent and predictive validity of a self-reported measure of medication adherence. Med Care. 1986;24(1):67-74.

21. BOT Plus 2 Web database. General Council of Official Colleagues of Pharmacists. [cited September 03, 2015]. Available from: https:// botplusweb.portalfarma.com/botplus.aspx. Accessed February 15, 2016.
22. e-Salud. Oblikue Consulting; 2015.[cited September 03, 2015]. Available from: http://www.oblikue.com/bddcostes/. Accessed February 15, 2016.

23. Arlandis S, Ruiz MA, Errando C, Villacampa F, Arumí D, Lizarraga I, Rejas J. Quality of life in patients with overactive bladder: validation and psychometric properties of the Spanish Overactive Bladder Questionnaire-short form. Clin Drug Investig. 2012;32(8):523-532.

24. Ruiz MA, Gutiérrez LL, Monroy M, Rejas J. Mapping of the OAB-SF Questionnaire onto EQ-5D in Spanish patients with overactive bladder. Clin Drug Investig. 2016;36(4):267-279.

25. Sacristan JA, Oliva J, Del Llano J, Prieto L, Pinto JL. What is an efficient health technology in Spain? Gac Sanit. 2002;16(4):334-343.

26. Caro JJ, Briggs AH, Siebert U, Kuntz KM; ISPOR-SMDM Modeling Good Research Practices Task Force. Modeling good research practices - overview: a report of the ISPOR-SMDM modeling good research practices task force-1. Value Health. 2012;15(6):796-803.

27. Rubio-Terrés C, Cobo E, Sacristán JA, Prieto L, del Llano J, Badia X; GrupoECOMED. Analysis of uncertainty in the economic assessment of health interventions. Med Clin (Barc). 2004;122(17):668-674.

28. Thompson SG, Barber JA. How should cost data in pragmatic randomised trials be analysed? BMJ. 2000;320(7243):1197-1200.

29. Garrison LP Jr, Neumann PJ, Erickson P, Marshall D, Mullins CD. Using real-world data for coverage and payment decisions: the ISPOR real-world data task force report. Value Health. 2007;10(5):326-335.

30. Sicras-Mainar A, Rejas J, Navarro-Artieda R, Aguado-Jodar A, RuizTorrejón A, Ibáñez-Nolla J, Kvasz M. Health economics perspective of fesoterodine, tolterodine or solifenacin as first-time therapy for overactive bladder syndrome in the primary care setting in Spain. BMC Urol. 2013;13:51.

31. Sicras-Mainar A, Rejas-Gutiérrez J, Navarro-Artieda R, Aguado-Jodar A, Ruíz-Torrejón A. Use of health care resources and associated costs in non-institutionalized vulnerable elders with overactive bladder treated with antimuscarinic agents in the usual medical practice. Actas Urol Esp. 2014;38(8):530-537.

32. Sicras-Mainar A, Navarro-Artieda R, Ruiz-Torrejón A, Sáez-Zafra M, Coll-de Tuero G. Persistence and concomitant medication in patients with overactive bladder treated with antimuscarinic agents in primary care. An observational baseline study. Actas Urol Esp. 2016;40(2):96-101.

33. Lopez-Bastida J, Oliva J, Antoñanzas F, García-Altés A, Gisbert R, Mar J, Puig-Junoy J. Spanish recommendations on economic evaluation of health technologies. Eur J Health Econ. 2010;11(5):513-520.

34. Çelik Gİ, Sütçü HK, Akpak YK, Akar ME. A flexible multidose GnRH antagonist versus a microdose flare-up GnRH agonist combined with a flexible multidose GnRH antagonist protocol in poor responders to IVF. Biomed Res Int. 2015;2015:970163.
ClinicoEconomics and Outcomes Research

\section{Publish your work in this journal}

ClinicoEconomics and Outcomes Research is an international, peerreviewed open-access journal focusing on health technology assessment, pharmacoeconomics and outcomes research in the areas of diagnosis, medical devices, and clinical, surgical and pharmacological intervention. The economic impact of health policy and health systems organization also constitute important areas of coverage. The manuscript management system is completely online and includes a very quick and fair peer-review system, which is all easy to use. Visit http://www.dovepress.com/testimonials.php to read real quotes from published authors. 